\title{
Article
}

Subscriber access provided by UiT Norges arktiske universitet

\section{Structure dependent determination of organophosphate targets in mammalian tissues using activity-based protein profiling}

Vivian S. Lin, Regan F Volk, Adrian J DeLeon, Lindsey N. Anderson, Samuel Owen

Purvine, Anil K. Shukla, Hans Christopher Bernstein, Jordan N. Smith, and Aaron T. Wright

Chem. Res. Toxicol., Just Accepted Manuscript • DOI: 10.1021/acs.chemrestox.9b00344 • Publication Date (Web): 24 Dec 2019

Downloaded from pubs.acs.org on January 5, 2020

\section{Just Accepted}

"Just Accepted" manuscripts have been peer-reviewed and accepted for publication. They are posted online prior to technical editing, formatting for publication and author proofing. The American Chemical Society provides "Just Accepted" as a service to the research community to expedite the dissemination of scientific material as soon as possible after acceptance. "Just Accepted" manuscripts appear in full in PDF format accompanied by an HTML abstract. "Just Accepted" manuscripts have been fully peer reviewed, but should not be considered the official version of record. They are citable by the Digital Object Identifier (DOI®). "Just Accepted" is an optional service offered to authors. Therefore, the "Just Accepted" Web site may not include all articles that will be published in the journal. After a manuscript is technically edited and formatted, it will be removed from the "Just Accepted" Web site and published as an ASAP article. Note that technical editing may introduce minor changes to the manuscript text and/or graphics which could affect content, and all legal disclaimers and ethical guidelines that apply to the journal pertain. ACS cannot be held responsible for errors or consequences arising from the use of information contained in these "Just Accepted" manuscripts. 


\title{
Structure dependent determination \\ of organophosphate targets in
}

\author{
mammalian tissues using activity-
}

\section{based protein profiling}

Vivian S. Lin ${ }^{\dagger}$, Regan F. Volk ${ }^{\dagger}$, Adrian J. DeLeon ${ }^{\dagger}$, Lindsey N. Anderson ${ }^{\dagger}$, Samuel O. Purvine ${ }^{\ddagger}$ Anil K. Shukla , Hans C. Bernstein ${ }^{\dagger / l}$, Jordan N. Smith ${ }^{\dagger}$, Aaron T. Wright ${ }^{+*}$

\author{
${ }^{\dagger}$ Biological Sciences Division, Pacific Northwest National \\ Laboratory, Richland, Washington 99354, United States \\ ${ }^{\ddagger}$ Environmental Molecular Sciences Laboratory, Pacific Northwest \\ National Laboratory, Richland, WA 99354, United States \\ SFaculty of Biosciences, Fisheries and Economics, UiT - The \\ Arctic University of Norway, Tromsø, 9019, Norway \\ "The Arctic Centre for Sustainable Energy, UiT - The Arctic \\ University of Norway, Tromsø, Norway \\ ${ }^{\perp}$ The Gene and Linda Voiland School of Chemical Engineering and \\ Bioengineering, Washington State University, Pullman, Washington \\ 99163 USA
}




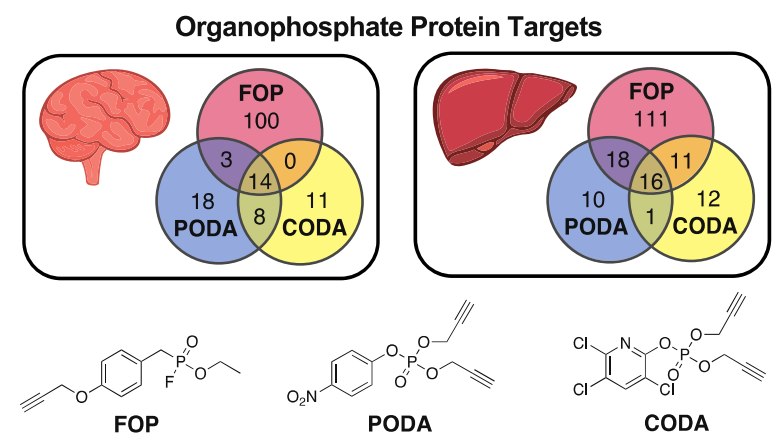

\section{ABSTRACT}

Acute and chronic exposure to organophosphates (OPs), including agricultural pesticides, industrial chemicals, and chemical warfare agents, remain a significant worldwide health risk. The mechanisms by which OPs alter development and cognition in exposed individuals remain poorly understood, in part due to the large number of structurally diverse OPs and the wide range of affected proteins and signaling pathways. To investigate the influence of structure on OP targets in mammalian systems, we have developed a series of probes for activity-based protein profiling (ABPP) featuring two distinct reactive groups that mimic OP chemical reactivity. FOP features a fluorophosphonate moiety, and PODA and CODA utilize a dialkynyl phosphate ester; both reactive group types target serine hydrolase activity. As the oxon represents the highly reactive and toxic functional 
group of many OPs, the new probes described herein enhance our understanding of tissue-specific reactivity of OPs. Chemoproteomic analysis of mouse tissues treated with the probes revealed divergent protein profiles, demonstrating the influence of probe structure on protein targeting. These targets also vary in sensitivity towards different OPs. The simultaneous use of multiple probes in ABPP experiments may therefore offer more comprehensive coverage of OP targets; FOP consistently labeled more targets in both brain and liver than PODA or CODA, suggesting the dialkyne warhead is more selective for enzymes in major signaling pathways than the more reactive fluorophosphonate warhead. Additionally, the probes can be used to assess reactivation of OP-inhibited enzymes by N-oximes and may serve as diagnostic tools for screening of therapeutic candidates in a panel of protein targets. These applications will help clarify the short- and long-term effects of OP toxicity beyond acetylcholinesterase inhibition, investigate potential points of convergence for broad spectrum therapeutic development, and support future efforts to screen candidate molecules for efficacy in various model systems.

TEXT

\section{Introduction}


Organophosphate (OP) pesticides, first developed in the 1940s, have been used worldwide in household and agricultural settings. ${ }^{1,} 2$ OPs have also long been used as chemical warfare agents and remain a threat to first responders and civilians. ${ }^{3}$ Currently, dozens of structurally diverse OPs are registered for agricultural, industrial, and pharmaceutical applications. While many OP pesticides, such as chlorpyrifos and malathion, display limited toxicity towards humans, metabolism of the thion species by cytochrome p450 oxidation and potentially other oxidative processes can generate the oxon, which serves as the active pesticide agent. ${ }^{4}$ Reactivity and metabolism of the oxon can proceed through a variety of different processes (Figure 1), such as hydrolysis by OP hydrolases (OPHs) and inhibition of various enzyme targets.

The acute toxicity of OPs can be attributed to their ability to covalently modify a serine residue in the active site of AChE (Figure 1). AChE inhibition results in accumulation of acetylcholine at neuromuscular junctions, which causes overstimulation of the nervous system and can lead to respiratory failure, convulsions, or paralysis. ${ }^{5}$ While the primary target of OPs is AChE, these compounds also inhibit other proteins in mammalian systems. ${ }^{6}{ }^{7}$ Regulatory and authoritative bodies have established public and occupational exposure limits based on cholinesterase inhibition, but 
examination of recent work suggests that non-cholinergic targets maybe as sensitive or more sensitive than acetylcholinesterase inhibition. Perturbation of these enzyme functions, particularly in the brain, is thought to be responsible for the long-term detrimental impacts of organophosphates on development and cognition, 8,9 which are still poorly understood. ${ }^{4}$

In order to understand the potential impacts of oP exposure beyond cholinergic targets, we sought to develop a series of molecular probes that could be used to broadly profile the targets of OPs in a variety of tissues using the activity-based protein profiling (ABPP) approach. ABPP employs activity-based probes (ABPS) that target enzymes based on their activity toward specific substrates. ${ }^{10,} 11$ ABPP has been used to study protein targets of serine hydrolases, ${ }^{12}$ glutathione S-transferases, ${ }^{13}$ cellulases, and other enzymes. ${ }^{14}$ To date, ABPP of secondary targets of OPs and OP-enzyme interactions has primarily focused on the use of fluorophosphonate-based probes, ${ }^{15-18}$ which have been widely used to study serine hydrolases. ${ }^{19}$ Recent efforts by Carmany et al. to profile targets of the organophosphate chemical weapon, VX agent, utilized an ABP probe featuring a thermal rearrangement to generate the active probe. ${ }^{20}$ Notably, OPs span a range of structures in terms of their reactive functionalities and leaving groups; these steric and electronic differences may affect their ability to bind and inhibit 
different proteins. A major challenge in OP therapeutic research has been addressing the divergent responses of OP-inhibited AChE toward chemical reactivating compounds and lack of a broad spectrum therapeutics for treatment of OP poisoning.5, 21 Some of the resistance to reactivation may arise from varying aging rates, depending on the electronics of the phosphate ester and the nature of the enzyme active site.22, 23 It is also established that OP agents have differing levels of inhibition of the primary target, $\mathrm{AChE}$, due to steric and electronic differences in both the leaving group and alkoxy substituents. ${ }^{24,} 25$ AChE inhibition may also differ across model organisms due to variation in the enzyme active site architecture. ${ }^{26}$ collectively, these observations underscore the complications associated with understanding toxicity for a wide range of OPs, as well as inherent differences in enzyme structure across model organisms and in different tissue types.

Given the structural diversity of OPs and observed differences in the response of OPs to various therapeutics, we anticipated that ABPs for OPs may display divergent profiles dependent upon structure. This hypothesis is supported by previous measurements of OP binding by AChE and studies demonstrating that structural changes to ABPs affect their ability to inhibit AChE and other targets. ${ }^{27,} 28$ Thereby, we sought to design new OP probes with structural features that 
would mimic the sterics, electronics, and reactive functionalities of representative OP compounds to examine the effect of probe structure on identified protein target in mammalian tissues (Figure 2A). We developed a new fluorophosphonate for OP profiling (FOP) by incorporating a benzyl group rather than an aliphatic or PEG linker, which provided structural similarity to the aromatic groups of PO and CPO. Additionally, we designed and synthesized two probes containing a dialkynyl phosphate ester as a new reactive group for ABPP of serine hydrolases; covalent modification of the enzyme occurs via a mechanism similar to that of phosphate ester pesticides, and the phenolic leaving groups are identical. Following validation that the ABPs inhibit AChE, the probes were applied to mouse brain and liver lysate to evaluate the impact of ABP structure and reactivity on identified targets, including shared and unique targets for each probe and susceptibility of targets to competition by OP pesticides (Figure 2B). We determined that the probes are excellent surrogates for authentic OPs and can be used to profile the broad and diverse impact of OPs on mammalian enzymes. Using these new probes, our research provides a significantly improved understanding of the targets of OPs across tissues. These results will help inform future studies exploring the long-term 
impacts of OPs on development, as well as improve probe design for $A B P P$ and usage in model systems.

\section{Experimental Procedures}

General materials and methods

Considering previous observations that fluorophosphonate probes hydrolyze when stored under neat conditions, ${ }^{29}$ probes were dissolved in anhydrous DMSO shortly after synthesis and characterization and divided into aliquots for longer term storage, avoiding freeze-thaw cycles.

Organophosphates were purchased from the following suppliers and used without further purification: paraoxon (Chem Cruz, sc-208151, Lot D2117) and chlorpyrifos oxon (98.8\%, Chem Service, MET-114590, Lot 525430). Stock solutions of OPs were prepared in dry DMSO and stored at $-70{ }^{\circ} \mathrm{C}$, avoiding freeze-thaw cycles. 2-pralidoxime chloride (2-PAM) was purchased from SigmaAldrich. Stock solutions of 2-PAM were prepared freshly on the day of the experiment in Millid water and maintained on ice. Electric eel acetylcholinesterase (Sigma-Aldrich) was prepared at $2 \mathrm{mg} / \mathrm{mL}$ concentration in $100 \mathrm{mM}$ PBS, pH 7.4, with 1 $\mathrm{mg} / \mathrm{mL}$ bovine serum albumin (BSA) and stored at $4{ }^{\circ} \mathrm{C}$ for up to 3 months.

Protein concentrations were determined using a bicinchoninic acid (BCA) assay (Thermo Scientific Pierce). 
Colorimetric assays were performed using a Molecular Devices plate reader.

Synthetic procedures are described in the supporting Information.

\section{Probe-mediated fluorescent labeling for SDS-PAGE}

Tissue lysate samples $(50 \mu \mathrm{L}$ at $1 \mathrm{mg} / \mathrm{mL}$ total protein concentration) were treated with $1 \mu \mathrm{L}$ DMSO vehicle control or 1 $\mu \mathrm{L} 2.5 \mathrm{mM}$ OP stock solution in DMSO (final concentration $50 \mu \mathrm{M}$ OP). Samples were incubated for $30 \mathrm{~min}$ at $37{ }^{\circ} \mathrm{C}$ with agitation and then treated with $1 \mu \mathrm{L}$ of a $500 \mu \mathrm{M}$ probe stock (final probe concentration $10 \mu \mathrm{M}$ ) for $1 \mathrm{hr}$ at $37^{\circ} \mathrm{C}$ with agitation. Samples were then subjected to click chemistry for 1 hr at r.t. by adding $0.5 \mu \mathrm{L}$ of $3 \mathrm{mM}$ carboxytetramethylrhodamine (TAMRA) azide, $1 \mu \mathrm{L} 250 \mathrm{mM}$ sodium ascorbate, $1 \mu \mathrm{L} 100 \mathrm{mM}$ tris(3hydroxypropyltriazolylmethyl) amine (THPTA), and 1 uL $200 \mathrm{mM}$ $\mathrm{CuSO}_{4}$. Samples were precipitated by adding $100 \mu \mathrm{L}$ cold $\mathrm{MeOH}$ and allowing to stand at $-70^{\circ} \mathrm{C}$ overnight. Precipitated protein was pelleted by centrifuging at $14,000 \mathrm{x} g$ for $15 \mathrm{~min}$ at $4{ }^{\circ} \mathrm{C}$, airdried after removal of supernatant, and reconstituted with 32.5 $\mu \mathrm{L}$ 1.2\% $\mathrm{SDS}$ in $1 \mathrm{X}$ PBS, $12.5 \mu \mathrm{L} 4 \mathrm{X}$ LDS buffer, and $5 \mu \mathrm{L} 10 \mathrm{X}$ reducing agent. Samples were sonicated briefly and then denatured at $85^{\circ} \mathrm{C}$ for $10 \mathrm{~min}$. Samples (15 $\mu \mathrm{L}$ per well) were loaded onto Invitrogen NuPAGE 4-12\% Bis-Tris protein gels (1.5 
mm, 15-well) with $2 \mu \mathrm{L}$ Amersham ${ }^{\mathrm{TM}}$ ECL $^{\mathrm{TM}}$ plex Fluorescent Rainbow Marker protein ladder (GE Healthcare). Gels were run in $1 \mathrm{X}$ MES SDS running buffer (Thermo Fisher) at $125 \mathrm{~V}$ for approximately 2 hr before imaging with a Typhoon FLA 9500 laser scanner using the Cy3/Cy5 settings.

After fluorescence imaging, gels were fixed in 50\% $\mathrm{MeOH}$ and 7\% acetic acid in Millig water for at least $30 \mathrm{~min}$ and then stained with GelCode ${ }^{\mathrm{TM}}$ Blue stain reagent (Thermo Fisher) overnight. After destaining in MilliQ water, the gel was imaged using a Gel Doc ${ }^{\mathrm{TM}}$ EZ Imager (Bio-Rad).

Enrichment of ABP-labeled proteins for chemoproteomics analysis Tissue lysate preparation is described in the Supporting Information. Tissue homogenate samples (500 $\mu \mathrm{L})$ were normalized to $1 \mathrm{mg} / \mathrm{mL}$ protein concentration using $250 \mathrm{mM}$ sucrose in PBS. Samples were incubated with PO or CPO competitor (1 $\mu \mathrm{L}$ of a 25 $\mathrm{mM}$ stock in DMSO) or DMSO vehicle for 30 min at $37{ }^{\circ} \mathrm{C}$ with agitation. Activity-based probes (1 $\mu \mathrm{L}$ of a $5 \mathrm{mM}$ stock for $10 \mu \mathrm{M}$ final concentration) or DMSO control was added to samples and incubated for 1 hr at $37^{\circ} \mathrm{C}$ with agitation. The final concentration of DMSO in all samples was $0.4 \% \mathrm{~V} / \mathrm{V}$. Click chemistry was performed using the following reagents for $500 \mu \mathrm{L}$ of probe-labeled sample: $3 \mu \mathrm{L}$ biotin-azide (10 mM in DMSO), $5 \mu \mathrm{L}$ sodium ascorbate (500 mM in water), $5 \mu \mathrm{L}$ tris(3- 
hydroxypropyltriazolylmethyl)amine (THPTA, $200 \mathrm{mM}$ in water), and $5 \mu \mathrm{L}$ of $\mathrm{CuSO}_{4}$ (400 mM in water). The samples were then agitated at $37^{\circ} \mathrm{C}$ for $1.5 \mathrm{hr}$. Precipitation of proteins was accomplished through the addition of $800 \mu \mathrm{L}$ cold $\mathrm{MeOH}$ to each sample. Samples were then placed in a $-80^{\circ} \mathrm{C}$ freezer for $1 \mathrm{hr}$. Samples were centrifuged, supernatant discarded, and pellets air dried for 30 min. To the samples, $520 \mu \mathrm{L}$ of $1.2 \%$ SDS in $1 \mathrm{X}$ PBS was added. Samples were heated to $95^{\circ} \mathrm{C}$ for $2 \mathrm{~min}$ and then sonicated for $6 \mathrm{~s}$, 1 s pulses. Samples were centrifuged and transferred to fresh Eppendorf tubes, leaving any residual pellet behind. A BCA assay was used to quantify the concentration of each sample. All samples were normalized to $0.65 \mathrm{mg} / \mathrm{mL}$.

All washes were performed using vacuum filtration. Biospin disposable chromatography columns (Bio-Rad Laboratories) were prepared by rinsing twice with $1 \mathrm{~mL} 1 \mathrm{X}$ PBS. $100 \mu \mathrm{L}$ streptavidinagarose beads were added to each column. The beads were rinsed twice with $1 \mathrm{~mL} 0.5 \% \mathrm{SDS}$ in PBS and twice with $1 \mathrm{~mL} 6 \mathrm{M}$ urea (prepared fresh in $25 \mathrm{mM} \mathrm{NH} \mathrm{HCO}_{3}, \mathrm{pH}$ 8), and four times in $1 \mathrm{~mL}$ 1X PBS. Beads were transferred to $4 \mathrm{~mL}$ cryovials using $2 \times 1 \mathrm{~mL}$ 1X PBS. $500 \mu \mathrm{L}$ of normalized probe-labeled lysate was added to corresponding Eppendorf tubes and another $500 \mu \mathrm{L}$ of $1 \mathrm{X}$ PBS was added. The cryovials were then rotated for 4 hr at $37{ }^{\circ} \mathrm{C}$. Samples were returned to columns with two rinses of $1 \mathrm{~mL}$ PBS. Samples 
were then washed twice with $1 \mathrm{~mL} 0.5 \%$ SDS in $1 \mathrm{X}$ PBS, $2 \times 1 \mathrm{~mL} 6$ M urea (prepared fresh in $25 \mathrm{mM} \mathrm{NH}_{4} \mathrm{HCO}_{3}, \mathrm{pH}$ 8), $2 \mathrm{x} 1 \mathrm{~mL}$ of Millie water, 8 × $1 \mathrm{~mL} 1 \mathrm{X} \mathrm{PBS}$, and $4 \times 1 \mathrm{~mL}$ of $25 \mathrm{mM} \mathrm{NH}_{4} \mathrm{HCO}_{3}$ (pH 8). Samples were then transferred to DNA lo-bind tubes (Sorensen) using 2 aliquots of $500 \mu \mathrm{L}$ of $1 \mathrm{X}$ PBS. The tubes were centrifuged at $10,500 \times \mathrm{g}$ for $5 \mathrm{~min}$ at room temperature. The supernatant was discarded, and beads were re-suspended in $200 \mu \mathrm{L}$ $25 \mathrm{mM} \mathrm{NH}_{4} \mathrm{HCO}_{3}(\mathrm{pH}$ 8). $0.08 \mu \mathrm{g}$ trypsin (supplier) was added to each bead mixture followed by incubation overnight at $37{ }^{\circ} \mathrm{C}$ with agitation. Samples were then centrifuged at 10,500 x $\mathrm{g}$ for 5 min and the supernatant was transferred to individually wrapped Eppendorf tubes. The samples were placed on a speedVac Concentrator (Savant SC110) until dry. Samples were reconstituted in $40 \mu \mathrm{L}$ of $25 \mathrm{mM} \mathrm{NH}_{4} \mathrm{HCO}_{3}$ and heated at $37^{\circ} \mathrm{C}$ for 5 min with agitation. $40 \mu \mathrm{L}$ of sample was transferred to thickwalled polycarbonate ultracentrifuge tubes (Beckman Coulter) and spun at 53,000 x $\mathrm{g}$ for $20 \mathrm{~min} .25 \mu \mathrm{L}$ of sample were then transferred to glass vials and stored at $-20^{\circ} \mathrm{C}$.

Mass spectrometry and data analysis

Liquid chromatography with tandem mass spectrometry (LC-MS/MS) acquisition 
Probe-labeled and no-probe (NP) control samples were analyzed using a Velos Orbitrap (Thermo Fisher) instrument using High Resolution MS (HMS) - Low resolution MS (MSn) acquisition according to the method previously described by sadler and coworkers. ${ }^{30}$ Briefly, samples were analyzed using a 100 min LCMS/MS method in which data were acquired 65 min after sample injection and $15 \mathrm{~min}$ into the LC gradient. Spectra were collected between $\mathrm{m} / \mathrm{z} 400$ to 2,000 at 100,000 resolution, followed by data-dependent ion trap generation of tandem MS (MS/MS) spectra of the six most abundant ions using 35\% collision energy and a dynamic exclusion time of $30 \mathrm{~s}$.

Probe-enriched data processing and analysis

Probe-enriched and NP-enriched brain and liver tissue sample data was analyzed independently using MaxQuant software (version 1.6.2.10) (11 $^{3}$ for feature detection and subsequent protein/peptide quantification. Datasets were grouped by treatment and MS/MS spectra was searched using a standard LC-MS run type against Mus musculus (strain C57BL/6J) UniProtKB database proteome file (UP000000589) (Downloaded in 04/12/2017 containing 16,857 reviewed entries; 8 entries listed as obsolete as of 07/05/2017). N-terminal protein acetylation and methionine oxidation were selected as variable modifications for all datasets. Peptides and proteins were processed using a maximum 
false discovery rate (FDR) of 0.01 ( 1\%). For increased peptide/protein (unique + razor) identification using small tissue sample collections, match between runs (MBR) was applied within an alignment time window of $20 \mathrm{~min}$ ( $3 \mathrm{~min}$ match window) . Unique peptides (peptide fragment is unique to a single protein sequence in the proteome file) were used for continued analysis, requiring a minimum peptide length of 7 amino acids for matching to a protein. Additional MaxQuant parameters were ran at software default entries.

Label-free quantification (LFQ) intensity data was $\log _{2}$ transformed using the "proteingroups.txt" output file, which required all unique peptide fragments to match to a single protein sequence in the .fasta file (protein count $=1 ;$ RAW $\log _{2}$ Pros tab), as described by Tyanova et al. ${ }^{31}$ LFQ values for each ABP control labeling group (PODA-ABP, CODA-ABP, and FOP-ABP with no $\mathrm{PO}$ or $\mathrm{CPO}$ inhibition) required an intensity values for $\geq 50 \%$ of the biological replicates for each not passing were excluded from further analysis. Protein values for ABP labeling were required to have a fold change $(F C) \geq 2$ over NP controls before being statistically compared to inhibitions datasets (ALL Probes tab in Supporting Information). For competition experiments, protein targets were determined as inhibited by the authentic OP if $\mathrm{a} \geq 2$ FC decrease was observed when comparing treated to 
untreated ABP measurements for each ABP. Those ABP targets passing criteria in NP and competition experiments were placed in the Biocyc gene set enrichment tool for mapping proteins to known biological pathways (GO biological/molecular/cellular terms). ${ }^{32}$ Gene set enrichment was set at a p-value cutoff of less than 0.001 ( 1\% FDR) using a Fisher Exact statistical approach for determining the most significantly represented proteins belonging to metabolic pathways for the organism Mus musculus. Enrichment results represent the top 10 best scoring metabolic pathways and the most highly represented proteins for those pathways for each ABP treatment and tissue type.

Oxime reactivation of $A C h E$

Electric eel AChE was diluted to $100 \mu \mathrm{g} / \mathrm{mL}$ and divided into $130 \mu \mathrm{L}$ volume samples. AChE was treated with a stoichiometric amount of OPs $(3 \mu \mathrm{M})$ for $30 \mathrm{~min}$ at $22{ }^{\circ} \mathrm{C}$, followed by $500 \mu \mathrm{M} 2-$ PAM for 1 hr. To remove any unreacted OP and excess oxime, samples were passed through a Zeba ${ }^{\mathrm{TM}}$ 7K MWCO spin desalting column (Thermo Fisher) which had been equilibrated with $3 \times 300$ $\mu \mathrm{L}$ 1X PBS, according to the manufacturer's instructions. The filtrate was collected and divided into $40 \mu \mathrm{L}$ samples, which were then treated with $10 \mu \mathrm{M}$ PODA, CODA, or FOP for $60 \mathrm{~min}$ at 22 ${ }^{\circ} \mathrm{C}$. Click chemistry using the previously described conditions was then performed. Cold methanol (80 $\mu \mathrm{L})$ was added to each 
sample to precipitate protein overnight at $-70{ }^{\circ} \mathrm{C}$. Precipitated proteins were isolated by centrifugation at 14,000 x $\mathrm{g}$ for 15 min at $4{ }^{\circ} \mathrm{C}$. The supernatant was removed by pipet and protein pellets were dried at r.t. Samples were reconstituted with $26 \mu \mathrm{L}$ 1.2\% SDS in 1X PBS, $10 \mu \mathrm{L} 4 \mathrm{X}$ LDS buffer, and $4 \mu \mathrm{L} 10 \mathrm{X}$ reducing agent. Samples were denatured at $85^{\circ} \mathrm{C}$ for $10 \mathrm{~min}$ and SDS-PAGE performed as described above. Densitometry was carried out using ImageQuantTL V8.1 analysis software; analysis of band intensities was performed using a rolling ball (radius 200) automatic background subtraction method for individual lanes. Band intensities were calculated and normalized to the average value of the vehicle control arbitrarily set to 1 .

\section{Results}

Characterization of the OP ABPs using the Ellman assay showed that all three new ABPs were AChE inhibitors in the high nanomolar to micromolar range. The probes were 30-fold weaker inhibitors of AChE compared to PO and CPO (Figure 3). FP2, a previously described fluorophosphonate probe for serine hydrolases, ${ }^{33}$ performed comparably to $\mathrm{PO}$ and $\mathrm{CPO}$ as an AChE inhibitor, with a nanomolar IC $_{50}$ value falling between the values determined for these two authentic OP pesticides.

Probe labeling of mouse tissue lysates and visualization by fluorescent detection on gels following SDS-PAGE showed distinct 
protein labeling profiles in different tissue types (Figure 4). FP2 had the lowest intensity of labeling by fluorescence in all four tissue types, while CODA produced the most intense labeling of proteins. Bands which did not appear diminished by either Po or CPO competition were observed in all tissues, particularly for CODA, highlighting the importance of competitive ABPP when confirming protein targets. ${ }^{34}$

After qualitatively confirming successful labeling of protein targets and competition with OPs in various tissue types by fluorescence SDS-PAGE, we used an enrichment protocol and mass spectrometry analysis to identify protein targets in brain and liver. Two of the most abundant protein targets of OPs identified in mouse brain and liver by mass spectrometry, APEH and CES1, were confirmed by Western blotting (Figure S1). Chemoproteomics analysis using LC-MS/MS is a quantitative and highly sensitive technique compared to SDS-PAGE and can elucidate both diversity and relative abundances of targets across all samples. Average sequence coverage for the top protein targets in both tissue types was 27\%. As shown in Figure 5, ABP targets passing criteria against control and competition experiments resulted in 154 in brain and 179 in liver. Consistent with previous ABPP studies of OP targets, the probes clearly identified major serine hydrolase targets of ops in both the liver and brain.16, 19, 35 Cholinergic targets AChE and BChE 
were labeled by all three probes in the brain and labeling was completely abolished in the presence of $\mathrm{PO}$ and CPO. In liver, however, CPO competition decreased but did not eliminate labeling of BChE. CODA also labeled BChE to a lesser extent relative to the other two probes. All three probes labeled a variety of carboxylesterases in the liver and were sensitive to PO and CPO inhibition of these targets. Furthermore, various lipid metabolizing enzymes involved in the endocannabinoid signaling pathway, including MAGL, FAAH, and ABHD6, were identified primarily in brain tissue but also in liver, although coverage by the ABPs varied among these targets.

Notably, the fluorophosphonate probe FOP detected 100 more targets in both brain and liver compared to the dialkyne probes PODA and CODA (Figure 4). In liver, FOP identified several glutathione S-transferases and cytochrome P450 enzymes, which were not detected using the other two probes.

Treatment of purified AChE that had been inhibited with PO and CPO was successfully reactivated by treatment with 2 -PAM and could be visualized using the fluorescent detection on SDS-PAGE gels with the OP ABPs (Figure 6). Reactivation of AChE upon treatment with 2 -PAM and recovery of enzyme activity was also confirmed through the Ellman assay (Figure S4).

\section{Discussion}


Prior ABPP studies focused on identification of OP secondary targets have relied on fluorophosphonate-based probes, although OPs feature a range of different reactive groups, including phosphate esters with phenolic or thiol leaving groups. To explore the influence of probe structure on identified proteins, we developed a series of new OP ABPs featuring two different reactive groups, the fluorophosphonate and a previously unexplored dialkynyl phosphate ester, that would closely mimic the reactive and structural properties of authentic OPs such as PO and CPO. Validation of the OP ABPs using purified enzyme and tissue lysates established these probes covalently bind to their expected cholinergic targets and act as AChE inhibitors. The higher IC $_{50}$ of the dialkynyl probes compared to the authentic OP pesticides may be attributed to the increased steric bulk of the propargyl compared to the ethyl groups. ${ }^{36}$ Further modification of the dialkynyl phosphate ester group, such as exploring asymmetric phosphate esters, may yield ABPs with improved reactivity as OP surrogates. Successful identification by CODA, PODA, and FOP of AChE in brain and BChE in brain and liver provided validation that all 3 probes covalently label these primary targets in tissue lysates; additionally, probe labeling was abolished by pretreatment of samples with CPO or PO, confirming that the $\mathrm{PO}$ and $\mathrm{CPO}$ compete 
with the probes for interaction and binding to the protein targets.

Variation in identified targets and target distribution The distribution of shared protein targets in brain compared to liver tissue varied depending on the probe type. In liver, PODA and CODA shared more targets with FOP than with one another (Figure 5). This suggests that structurally, the difference in leaving group has a larger influence on target labeling than the fluorophosphonate vs. the dialkyne warhead. However, in brain, PODA and CODA displayed more shared targets between each other than with FOP. Compared to fluorophosphonates, the dialkynyl phosphate ester warhead is less susceptible to hydrolysis and less reactive in vitro, yielding more selective protein profiles with more shared than unique targets. The higher reactivity of fluorophosphonate ABPs relative to dialkynyl phosphate ester probes may be attributed to a combination of sterics as well as leaving group ability, with the fluoride acting as a better leaving group than the phenolates in aqueous conditions. ${ }^{37}$

OPs have been extensively studied for their ability to inhibit serine hydrolases in a multitude of model systems. The role of these enzymes in neuropeptide turnover and regulation of signaling molecules in the nervous system may be of particular 
interest for probing the cognitive impacts of OPs. ${ }^{38}$ Top serine peptidase targets in brain (Figure 5), including acylpeptide hydrolase (APEH), 9, 39 prolyl endopeptidase (PREP), 9, 15 cathepsin A (CTSA), 40 and prolylcarboxypeptidase (PRCP) 41 were perturbed by PO and $\mathrm{CPO}$ in relatively similar ways. In contrast, other peptidases identified in brain were primarily labeled by FOP, including isoaspartyl peptidase (ASRGL1), which may affect neurotransmitter production, and serine protease HTRA1, ${ }^{42}$ which may be involved in TGF- $\beta$ signaling and $\beta$-amyloid precursor protein processing pathways. ${ }^{43}$

Impacts of organophosphates on lipid metabolism Previous studies have used ABPP to examine pathways in mammalian model systems affected by OP exposures, frequently identifying significant numbers of enzymes involved in lipid metabolism for both brain and liver tissue. ${ }^{35}$ Paraoxon is known to inactivate a broad range of lipases in different tissues and has been used as a general lipase inhibitor in biochemical studies.44, 45 We confirmed our new ABPs performed as excellent mimics of authentic OPs through successful identification of major secondary targets of OPs by mass spectrometrychemoproteomics and validation of these targets through competition experiments. PODA, CODA, and FOP identified key enzymes involved in lipid metabolism, including several targets 
in the endocannabinoid signaling pathway (FAAH, MAGL, and ABHD6), 28, 46-48 acyl-protein thioesterases (LYPLA1 and LYPLA2), and platelet activating factor acetylhydrolases (PAFAH, PAFAH1B2, PAFAH1B). OP exposure levels that inhibit these targets in the brain may be well below the threshold for acute inhibition of AChE, underscoring the need for further investigation of the downstream effects of OPs on these sensitive signaling pathways. The probes did not label all of these targets in the same manner (Figure 5), indicating selectivity for some proteins depending on probe structure and reactivity. Given the importance of lipases and lipid signaling in brain, ${ }^{49-51}$ the effects of OPs on lipid metabolism has been proposed as a major contributing factor to the long-term negative impacts of OP exposure on development and cognitive function. 52

Our OP ABPs represent new tools for profiling these important enzymes in the brain and other tissues that react with different OP structures. Furthermore, based on the results of this study, specific probes may be better suited for selective ABPP of specific lipases, or a cocktail of probes can be used for more comprehensive coverage of diverse lipid metabolizing enzymes. The varying sensitivities of lipid metabolizing enzymes to both OP competition and the different probes suggest the new OP ABPs developed in this study may be used to further probe 
specific lipase targets by ABPP (Figure 5). These findings highlight the complexities involved with determining oP interactions with proteins using ABPP, and taken together, emphasize how differences in molecular structure and reactivity of both the authentic OPs and probes are crucial considerations in ABPP-based target identification.

Organophosphate hydrolases

Paraoxonases are organophosphate hydrolases (OPHs) that degrade OPs by catalyzing the hydrolysis of the leaving group, rendering the compound less electrophilic and generally less toxic. Paraoxonase-1 (PON1) is known to catalyze the hydrolysis of PO, CPO, and fluorophosphonate OPs such as sarin, soman, and VX, ${ }^{53}$ and has been proposed as a major factor influencing oP susceptibility on an individual basis. ${ }^{4}, 53$ Surprisingly, all three newly developed ABPs covalently labeled PON1 (Figure 5), which has not been previously reported in ABPP studies. The action of OpHs would mechanistically have been expected to yield hydrolyzed, and therefore inactive, probes. PODA was only partially competed by $\mathrm{PO}$ and $\mathrm{CPO}$, while both CODA and FOP were highly sensitive to OP competition as enrichment was completely ablated by $\mathrm{PO}$ and CPO. These initial findings suggest PODA, CODA, and FOP may be useful ABPs for investigating PON1 activity in complex protein mixtures. Structural examination of the 
hydrolytic abilities of PON1 have previously observed that steric modification of the alkoxy groups on the phosphate ester can lead to inhibition of the enzyme, with groups larger than an ethyl resulting in loss of OPH activity. ${ }^{54}$ Further exploration of the probe labeling site on PON1 is needed to determine the impact of OP ABP binding on OPH activity.

Points of convergence in OP targets

Since the increase in OP pesticide and nerve agent development in the mid-1900s, there have been intensive efforts to identify chemical medical countermeasures to mitigate the short-term effects of OPs, primarily through reactivation of OPinhibited AChE. However, the long-term effects of OP exposure remain poorly understood, but are thought to involve noncholinergic, secondary targets of OP compounds. Efforts to develop treatments for OP exposures are therefore focusing on therapeutics that will act on these secondary targets in addition to AChE.

Utilization of OP competition with the ABPP platform has allowed for streamlined, one-pot screening of multiple secondary targets of OPs in a given sample. Notably, identification of highly sensitive, shared targets across multiple tissue types and OPs may yield major points of convergence that can be pursued for broad spectrum therapeutic development. Following 
identification of targets by ABPP, further validation using specific activity assays is needed to determine whether the enzyme targets are activated, inhibited, or unaffected by the labeling event. In our study, we identified MAGL, CTSA, APEH, PREP, and PRCP in both the brain and liver as major targets of all 3 probes with a broad range of affected pathways, including serine hydrolase and peptidase activities (Figure SI5). Having demonstrated these new probes can provide a measure of functional activity and $O P$ sensitivity of these critical targets in complex protein mixtures, we envision application of this ABPP platform to more directed screening efforts of these and other targets for broad spectrum therapeutic and prophylaxis development in the future.

\section{Oxime reactivators}

The currently accepted treatment for nerve agent exposure in the U.S. involves intramuscular administration of atropine, a muscarinic agonist, and 2-pralidoxime (2-PAM), an N-oxime reactivator of AChE. ${ }^{55}$ However, the effectiveness of currently available therapeutic oximes, including 2-PAM, in reactivating OP-inhibited AChE in patients is controversial. ${ }^{6}$ Efforts that have centered on identifying oxime and non-oxime AChE reactivators must demonstrate compounds successfully reach key tissues, including the brain, remain stable under field storage 
conditions, and display minimal toxicity and off-target effects. Most oximes developed for AChE reactivation also act as reversible AChE inhibitors and exhibit differential efficacy against various OP nerve agents and pesticides.5, 57, 58 Furthermore, positively charged, bulky pyridinium N-oximes typically cannot cross the blood-brain barrier, although structural modifications to increase lipophilicity have facilitated penetration into the brain. ${ }^{5}$ Uncharged N-oximes as well as non-oxime AChE reactivators have been developed as possible alternatives.56, 60, 61 Other strategies to reduce toxic exposure to OPs have been explored, including prophylactics to prevent inhibition of AChE by OP agents ${ }^{62,} 63$ and screening or directed evolution of bioscavenger enzymes for stoichiometric or catalytic hydrolysis of OP compounds.64-68

Despite these diverse approaches to reversing or preventing OP toxicity, development of widely applicable compounds and strategies for therapeutic intervention following or preceding OP exposure continues to be a significant need. Delivery of therapeutics, their metabolism in vivo, and their dosage vs. concentration in target tissues are critical considerations. While reactivation or protection of the primary target, AChE, is essential for saving life, the potential long-term impacts of OP exposure due to effects on secondary targets are also an area of 
concern that must be addressed in broad spectrum therapeutic development.

We demonstrate that ABPP can be used as a platform to screen for therapeutics that reactivate AChE and potentially other enzyme targets. Treatment of PO- and CPO-inhibited AChE with 2-PAM successfully recovered the majority of enzyme activity as demonstrated by both the Ellman assay (Figure S3) and ABPP using these three new probes (Figure 6). We envision that this ABPP approach to screening candidate molecules will assist in the evaluation of drug compounds for reactivation of OP-inhibited cholinergic targets as well as enzymes involved in other diverse pathways. The flexibility of the ABPP platform and ease of probe application to samples will facilitate their use in therapeutic screening and target identification and may assist in discovery efforts for efficacious treatment and mitigation of both short- and long-term effects of OPs.

\section{Conclusion}

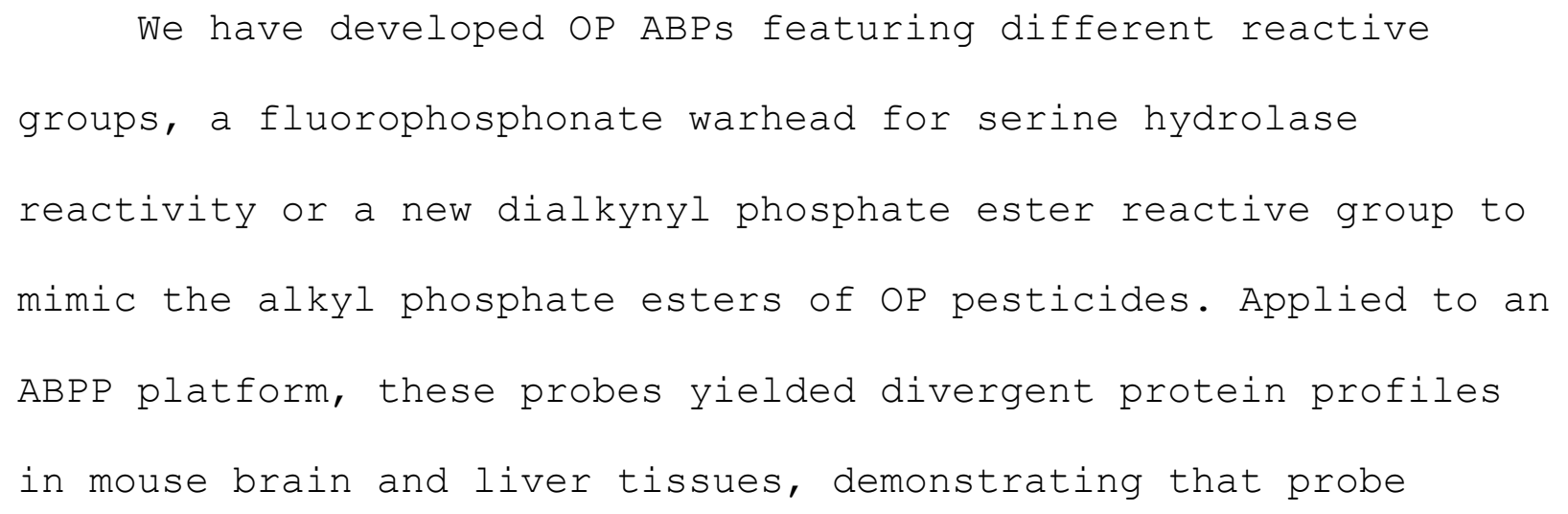


structure plays an important role in target identification and advocates for a probe cocktail approach to broadly identify and assess as many potential OP targets as possible. Competition experiments using $\mathrm{PO}$ and $\mathrm{CPO}$ also revealed variations in target distribution and sensitivity toward the different ABPs and selected OP pesticides; the fluorophosphonate probe FOP consistently labeled more unique targets, while the dialkyne probes PODA and CODA generated profiles with predominantly shared targets. These results provide a foundation for further refinement of the probe structures and inspiration for new probe designs, not only for ABPP of OP targets, but also for the development and evaluation of prophylactic or therapeutic treatments for OP exposure.

Our ABPP developments will enable deeper investigations to improve our understanding of OP impacts on human health. They represent a capability expansion that can be used in preventing and addressing the toxic effects of OP exposure. The search for broad spectrum therapeutics to treat the toxic effects of oPs is ongoing, and identification of shared targets for multiple ops may provide focal points for advancing countermeasure development. Implementation of a streamlined ABPP platform using these probes for screening therapeutic candidate molecules across various animal models will enable evaluation of treatment efficacy for multiple targets in complex protein mixtures. 


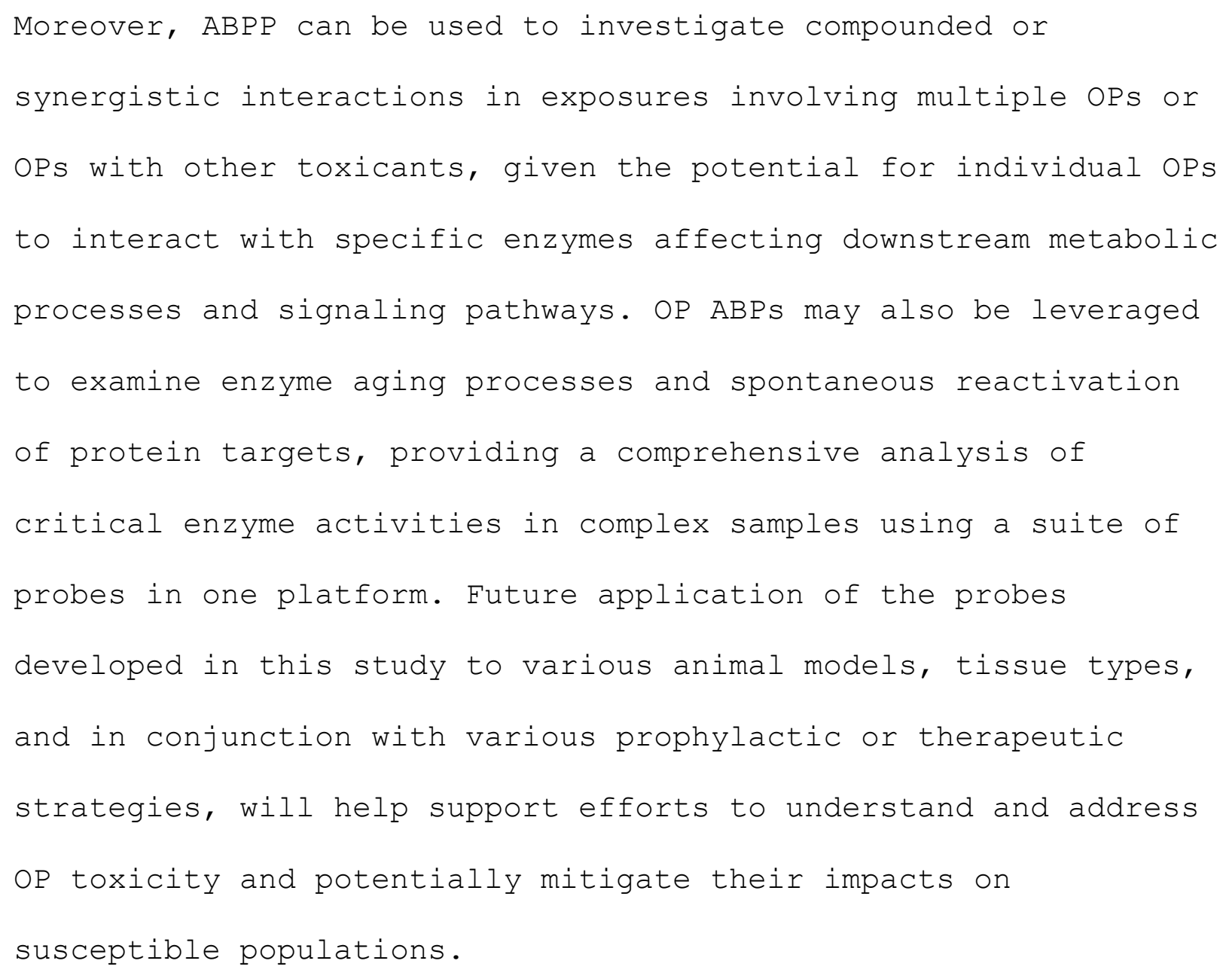

FIGURES 


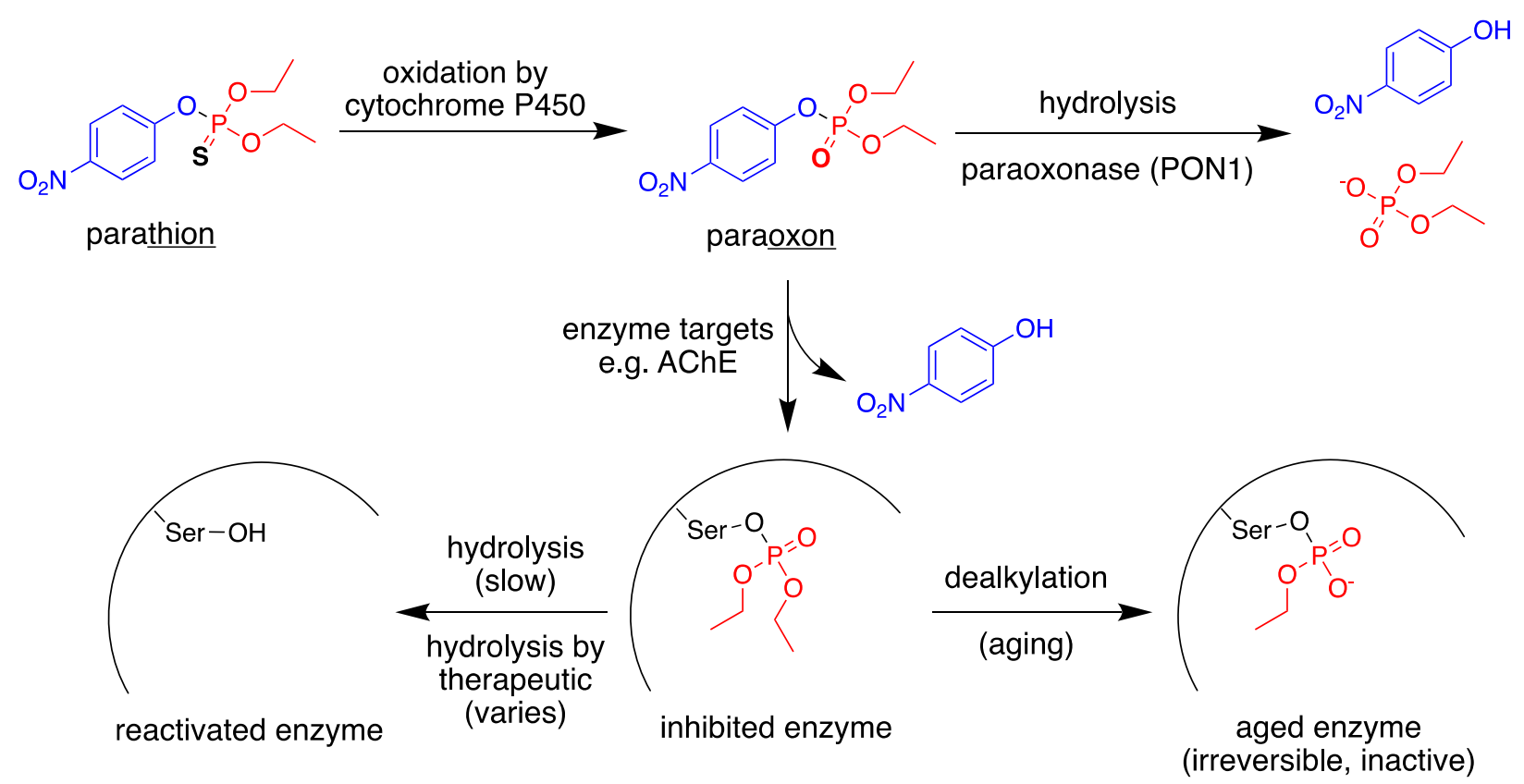

Figure 1. Pathways for reactivity and metabolism of OP pesticides. Oxidation of the thion to the more reactive oxon can lead to toxicity through enzyme inhibition and inactivation. 
A
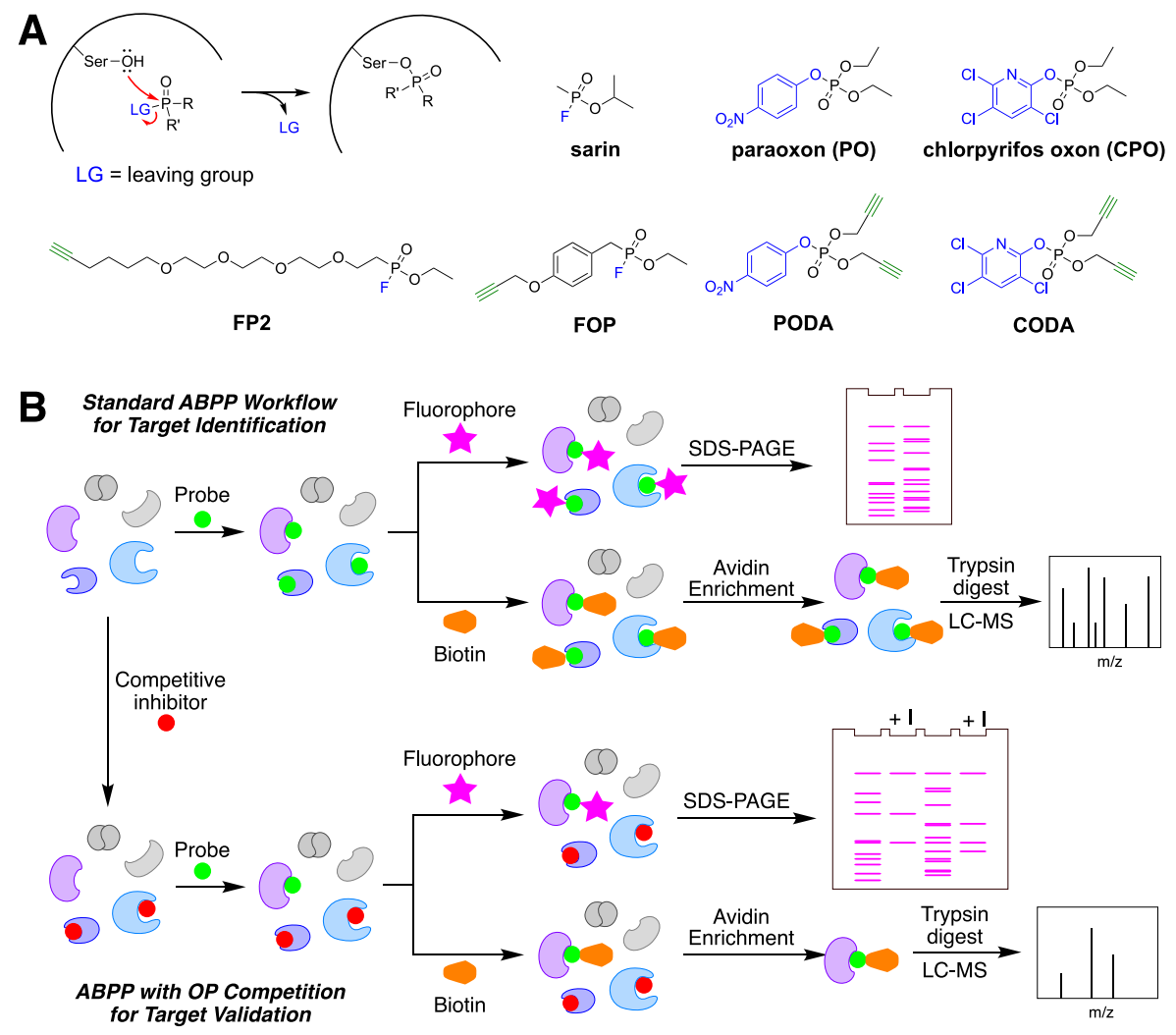

Figure 2. Activity-based protein profiling (ABPP) using OP activity-based probes (ABPs). (A) Mechanism of covalent labeling of serine hydrolases by organophosphates and structures of selected OPs and OP ABP designs. The leaving group (blue) is essential for reactivity with nucleophilic residues in protein targets. Incorporation of the alkyne (green) into the OP ABPs allows for click chemistry to attach a fluorophore for SDS-PAGE or biotin group for pulldown of the protein-probe adduct and subsequent LC-MS/MS proteomics analysis. (B) ABPP workflow for standard target identification and validation using competitive ABPP. 

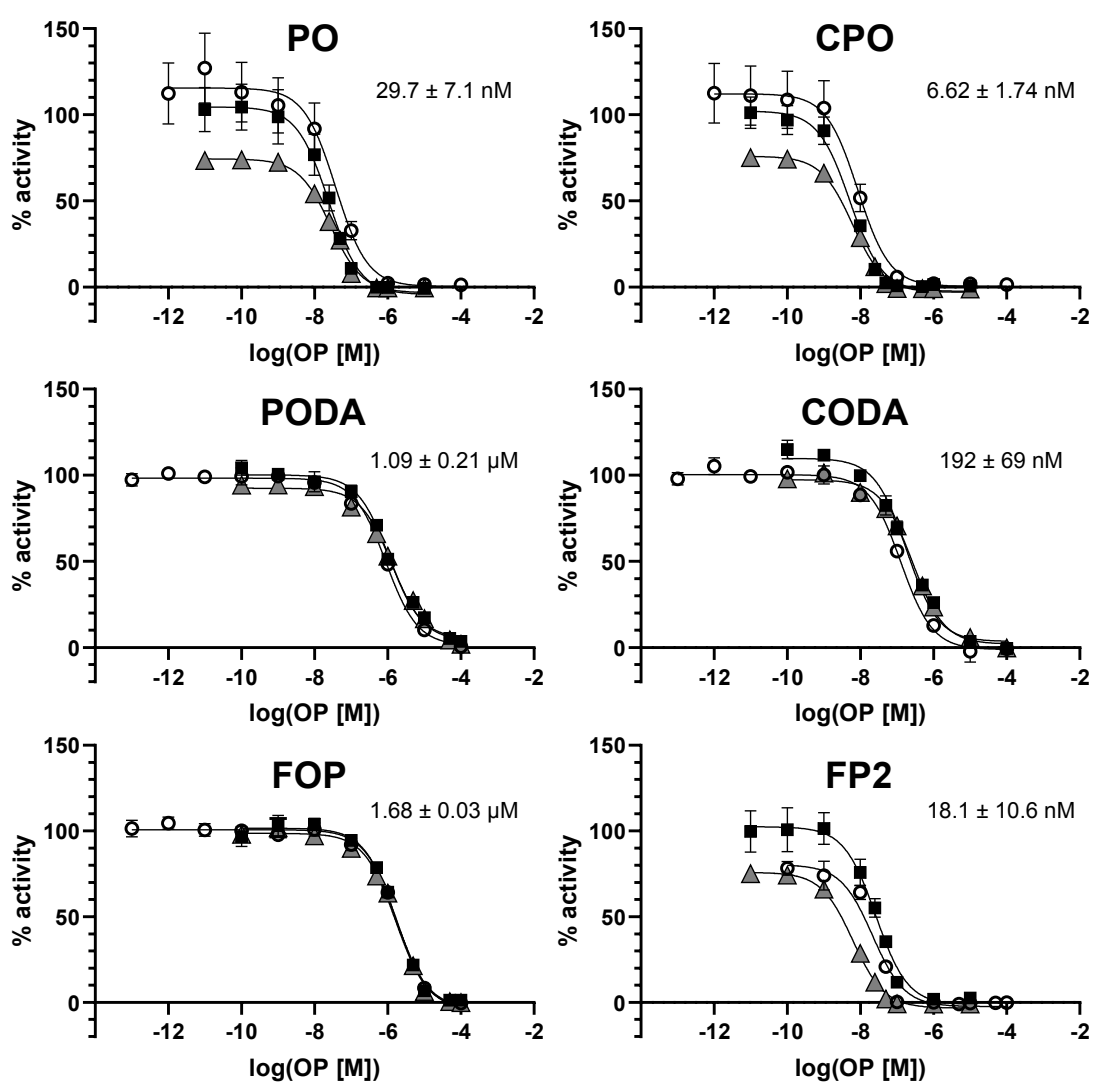

Figure 3. Half maximal inhibitory concentration ( $\left.\mathrm{IC}_{50}\right)$ determination for OP ABPs and authentic OP pesticides, establishing the relative effectiveness of these compounds as AChE inhibitors. Activity of electric eel AChE was determined using an Ellman's assay after treating samples with OPs, ABPs, or DMSO vehicle $(0.2 \% \mathrm{v} / \mathrm{v})$ for $30 \mathrm{~min}$. Symbols indicate data from three independent experiments. Error bars represent \pm s.d. for each replicate. 

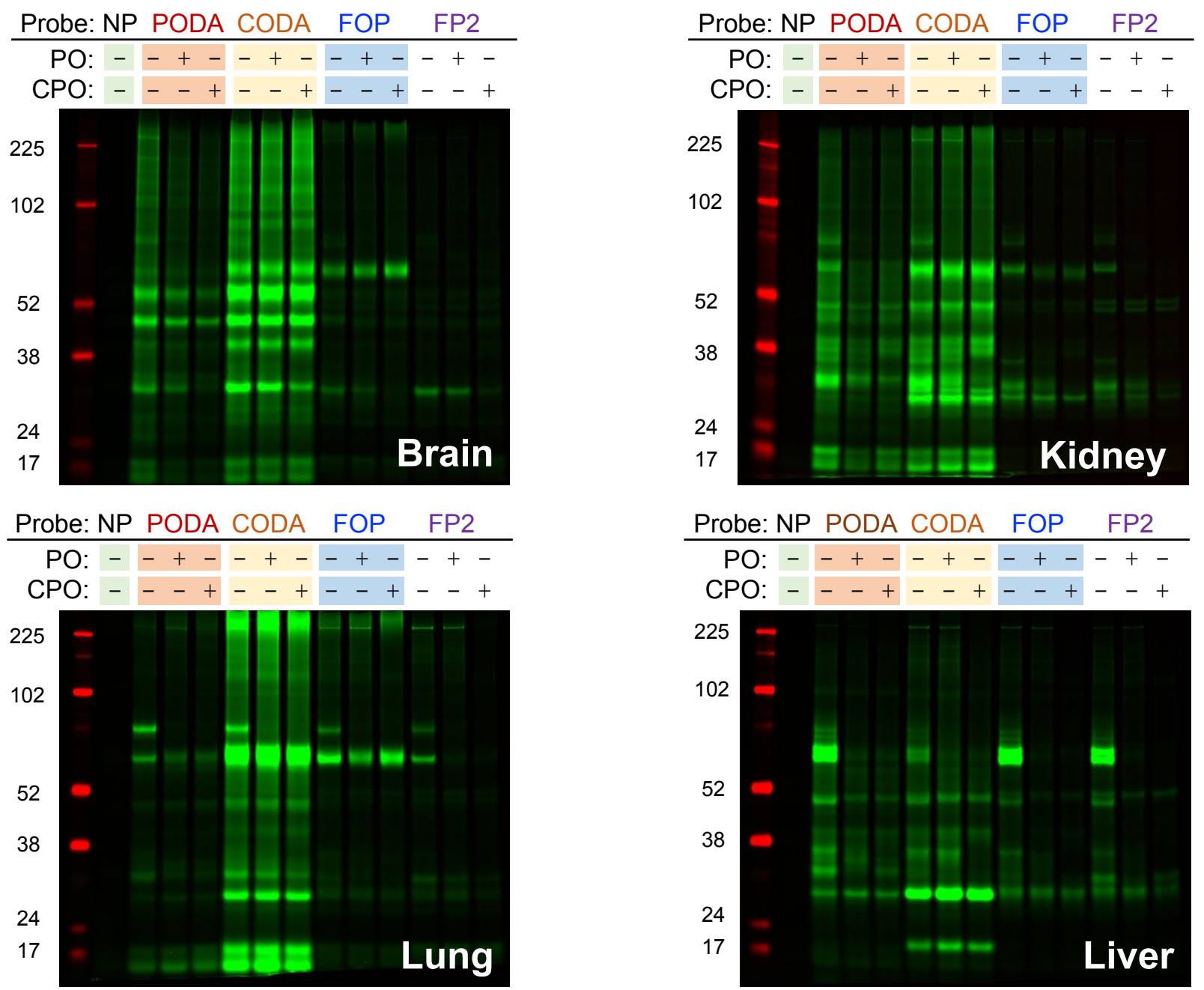

Figure 4. Protein targets identified by ABPP in mouse tissues using a suite of OP ABPs (PODA, CODA, FOP, and FP2), as visualized by fluorescent detection on SDS-PAGE gels. Mouse brain, kidney, lung, and liver tissue lysates were treated with DMSO vehicle, PO, or CPO (50 $\mu \mathrm{M})$ for $30 \mathrm{~min}$, followed by probe labeling $(10 \mu \mathrm{M})$ for 1 hr at $37^{\circ} \mathrm{C}$ and click chemistry with TAMRA azide for 1 hr. Stained protein images for these gels are in the Supplementary Information. NP = no-probe control. 


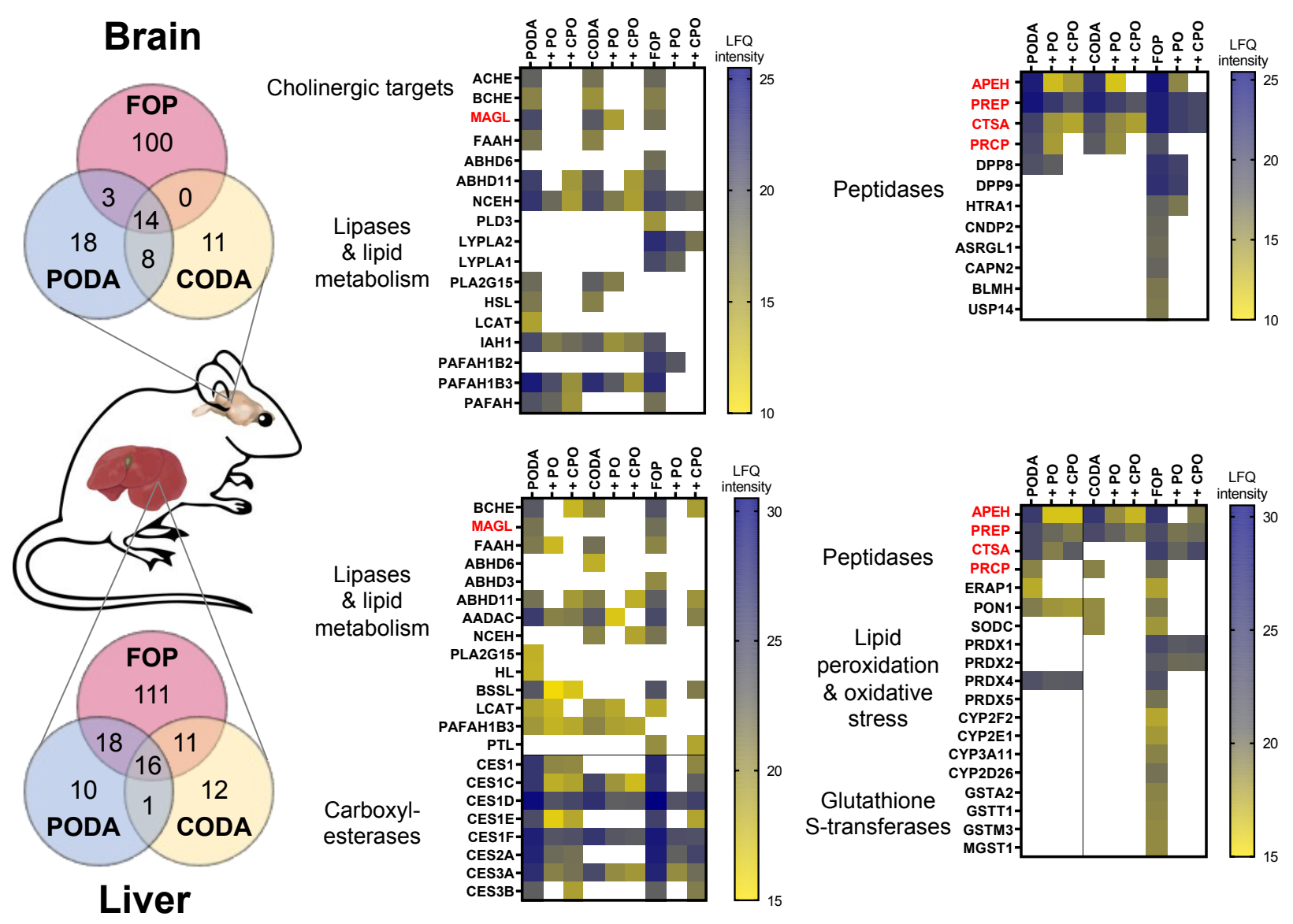

Figure 5. LC-MS/MS chemoproteomics identification of target distribution in mouse brain and liver S9 fractions. Venn diagrams show unique and shared OP-responsive targets for each probe. Heatmaps show sensitivities of targets to each probe and PO or CPO competition in brain and liver as averaged label-free quantification (LFQ) intensities. Proteins highlighted in red were identified as the most significantly represented targets of OP ABPs in a broad range of affected metabolic pathways in both brain and liver. Samples $(\mathrm{n}=4)$ were treated with PO or CPO (50 $\mu \mathrm{M})$ or DMSO vehicle $(0.4 \% \mathrm{v} / \mathrm{v})$ for $30 \mathrm{~min}$ followed by labeling 
with $10 \mu \mathrm{M}$ probe for 1 hr at $37^{\circ} \mathrm{C}$. ABP target abundances were required to have a fold change $\geq 2$ over no-probe control samples; additionally, results were filtered to exclude targets that were unresponsive to OP competition, determined using a fold change $\geq$ 2. White boxes indicate targets for which there were missing values for $>50 \%$ of the biological replicates.
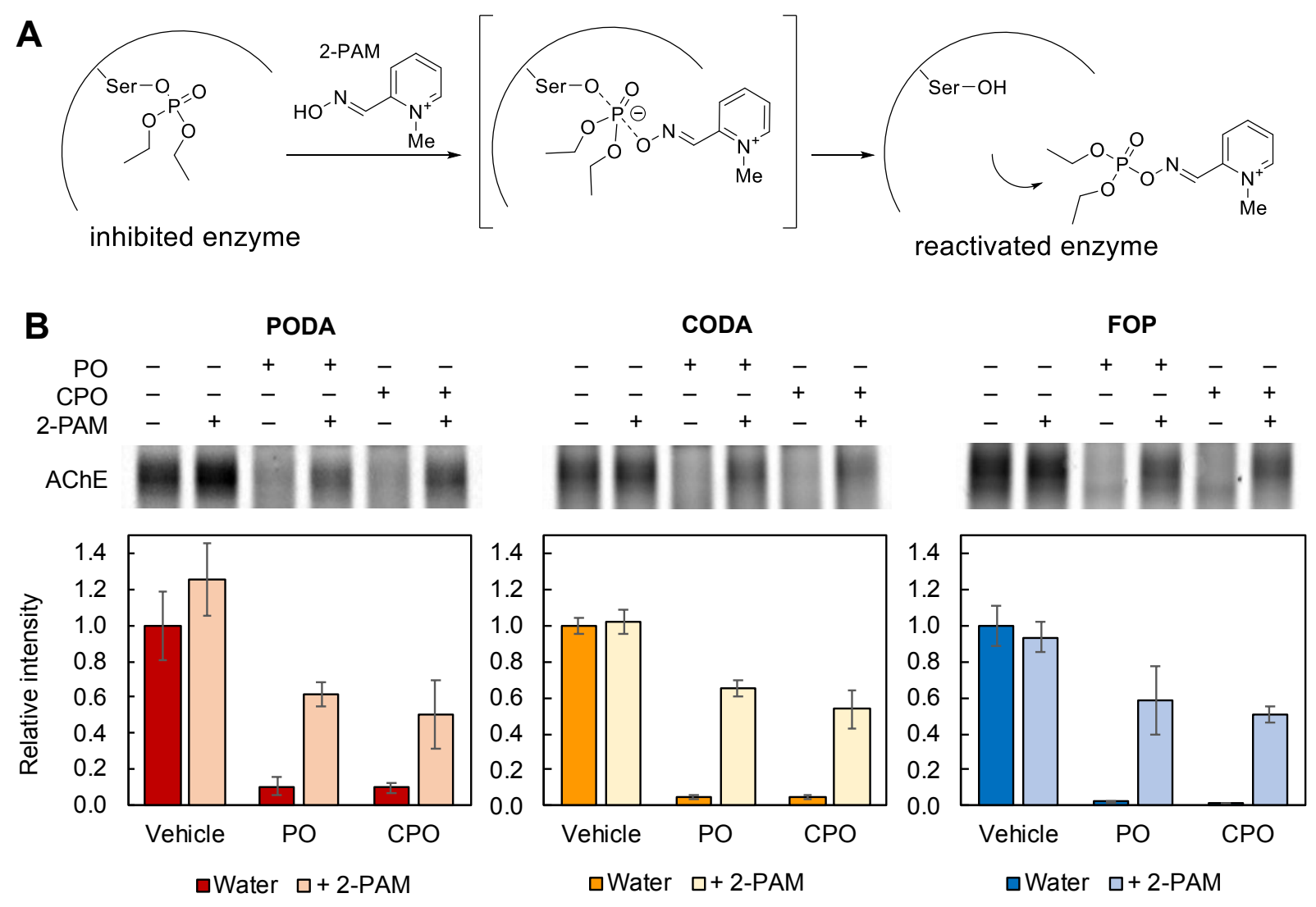

Figure 6. Oxime reactivation of OP-inhibited enzymes. (A) Mechanism by which OP-inhibited enzymes can be reactivated by 2pralidoxime (2-PAM). (B) Reactivation of $3 \mu \mathrm{M} \mathrm{PO}-$ and CPOinhibited eel AChE by $500 \mu \mathrm{M}$ 2-PAM, determined by fluorescent 
detection of OP ABP-labeled protein on SDS-PAGE gels. Error bars represent \pm s.e.m. for 3 technical replicates. Full fluorescence and stained protein images of gels are in the SI.

\section{ASSOCIATED CONTENT}

\section{Supporting Information}

The Supporting Information is available free of charge on the ACS Publications website:

- Methods for tissue lysate preparation, Ellman assay for AChE activity, and Western blotting; images of total protein staining for SDS-PAGE gels; Western blots for APEH and CES1; Ellman assay for N-oxime mediated reactivation of AChE; distribution of most well-represented proteins observed in top hit enriched metabolic pathways; probe synthesis and characterization.

- Full list of proteins identified using ABPP, analysis mapping to metabolic pathways

AUTHOR INFORMATION

Corresponding Author

*Aaron T. Wright, email: aaron.wrightepnnl.gov

\section{Author Contributions}


The manuscript was written through contributions of all authors. VSL, RFV, AJD, JNS, ATW designed the experiments. VSL, RFV, AJD, AKS conducted experiments. VSL, LNA, SOP, ATW analyzed proteomics. All authors have given approval to the final version of the manuscript.

\section{Funding Sources}

This research was supported by funding from the National Security Directorate Seed Initiative (H.C.B.), a Laboratory Directed Research and Development (LDRD) Program of Pacific Northwest National Laboratory (PNNL) and an Open Call LDRD grant (J.N.S.) and employed proteomics capabilities supported by the NIH NIGMS Research Resource for Integrative Biology (P4I GM103493). A portion of the research was performed using EMSL, a DOE Office of Science User Facility sponsored by the Office of Biological and Environmental Research. PNNL is a multiprogram laboratory operated by Battelle for US DOE Contract DE-AC0676RL01830.

\section{Notes}

The authors declare no competing financial interests. The mass spectrometry proteomics data have been deposited to the ProteomeXchange Consortium via the PRIDE $^{69}$ partner repository with the dataset identifier PXD015072. 


\section{ACKNOWLEDGMENT}

We thank Josh Hansen and Heather Brewer for assistance and advice with proteomics sample preparation, and Matt Gaffrey and Ryan Sontag for their help with Western blotting. We are also grateful to Paul Piehowski for mass spectrometry analysis and Sarah Burton for NMR support. We would like to acknowledge Kristopher Abney, Natalie Sadler, Ethan Stoddard, and Christopher Whidbey for performing mouse dissection and tissue collection. We thank Kristoffer Brandvold, Susan Ramos-Hunter, and Kristopher Abney for helpful ideas and discussion.

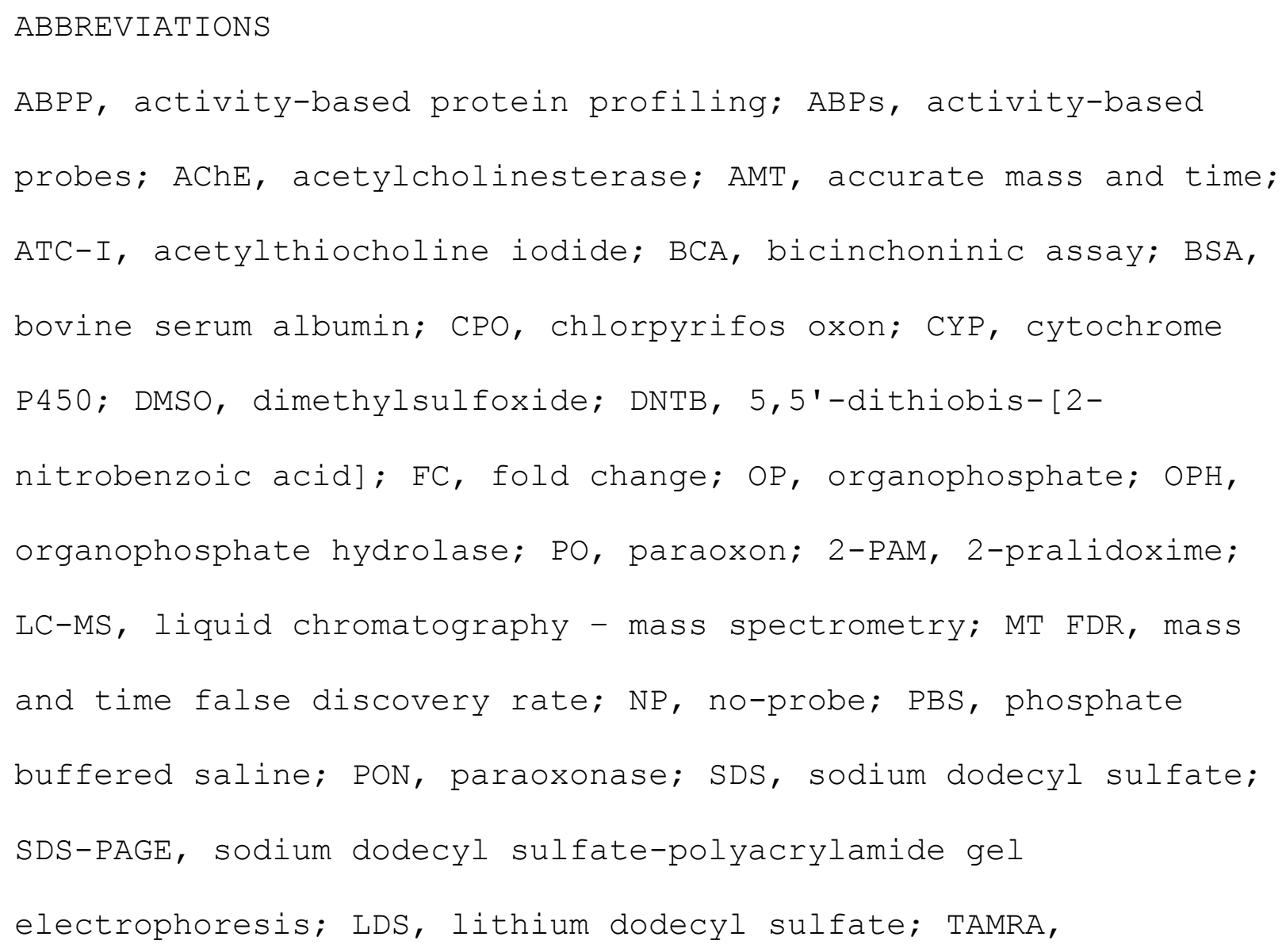


carboxytetramethylrhodamine; THPTA, Tris (3-

hydroxypropyltriazolylmethyl) amine

\section{REFERENCES}

1. Costa, L. G., Organophosphorus Compounds at 80: Some Old and New Issues. Toxicol Sci 2018, 162 (1), 24-35.

2. Casida, J. E.; Durkin, K. A., Anticholinesterase insecticide retrospective. Chem Biol Interact 2013, 203 (1), 221-5.

3. Worek, F.; Wille, T.; Koller, M.; Thiermann, H., Toxicology of organophosphorus compounds in view of an increasing terrorist threat. Arch Toxicol 2016, 90 (9), 2131-2145.

4. Eaton, D. L.; Daroff, R. B.; Autrup, H.; Bridges, J.; Buffler, P.; Costa, L. G.; Coyle, J.; McKhann, G.; Mobley, W. C.; Nadel, L.; Neubert, D.; Schulte-Hermann, R.; Spencer, P.

S., Review of the toxicology of chlorpyrifos with an emphasis on human exposure and neurodevelopment. Crit Rev Toxicol 2008, 38 Suppl 2, 1-125.

5. Eddleston, M.; Buckley, N. A.; Eyer, P.; Dawson, A. H., Management of acute organophosphorus pesticide poisoning. The Lancet 2008, 371 (9612), 597-607.

6. Casida, J. E.; Quistad, G. B., Organophosphate toxicology: safety aspects of nonacetylcholinesterase secondary targets. Chem Res Toxicol 2004, 17 (8), 983-98.

7. Terry, A. V., Jr., Functional consequences of repeated organophosphate exposure: potential non-cholinergic mechanisms. Pharmacol Ther 2012, 134 (3), 355-65.

8. Smith, J. N.; Hinderliter, P. M.; Timchalk, C.; Bartels, M. J.; Poet, T. S., A human lifestage physiologically based pharmacokinetic and pharmacodynamic model for chlorpyrifos: development and validation. Regul Toxicol Pharmacol 2014, 69 (3), 580-97.

9. $\quad$ Pancetti, F.; Olmos, C.; Dagnino-Subiabre, A.; Rozas, C.; Morales, B., Noncholinesterase effects induced by organophosphate pesticides and their relationship to cognitive processes: implication for the action of acylpeptide hydrolase. $J$ Toxicol Environ Health B Crit Rev 2007, 10 (8), 623-30.

10. Cravatt, B. F.; Wright, A. T.; Kozarich, J. W., Activity-based protein profiling: from enzyme chemistry to proteomic chemistry. Annu Rev Biochem 2008, 77, 383-414.

11. Willems, L. I.; Overkleeft, H. S.; van Kasteren, S. I., Current developments in activitybased protein profiling. Bioconjug Chem 2014, 25 (7), 1181-91.

12. Liu, Y.; Patricelli, M. P.; Cravatt, B. F., Activity-based protein profiling: The serine hydrolases. Proceedings of the National Academy of Sciences 1999, 96 (26), 14694-14699.

13. Stoddard, E. G.; Killinger, B. J.; Nair, R. N.; Sadler, N. C.; Volk, R. F.; Purvine, S. O.; Shukla, A. K.; Smith, J. N.; Wright, A. T., Activity-Based Probes for Isoenzyme- and SiteSpecific Functional Characterization of Glutathione S-Transferases. J Am Chem Soc 2017, 139 (45), 16032-16035.

14. Evans, M. J.; Cravatt, B. F., Mechanism-based profiling of enzyme families. Chem Rev 2006, 106 (8), 3279-301.

15. Tuin, A. W.; Mol, M. A.; van den Berg, R. M.; Fidder, A.; van der Marel, G. A.; Overkleeft, H. S.; Noort, D., Activity-Based Protein Profiling Reveals Broad Reactivity of the Nerve Agent Sarin. Chem Res Toxicol 2009, 22 (4), 683-9. 
16. Ross, M. K.; Pluta, K.; Bittles, V.; Borazjani, A.; Allen Crow, J., Interaction of the serine hydrolase KIAA1363 with organophosphorus agents: Evaluation of potency and kinetics. Arch Biochem Biophys 2016, 590, 72-81.

17. Jacob, R. B.; Michaels, K. C.; Anderson, C. J.; Fay, J. M.; Dokholyan, N. V., Harnessing Nature's Diversity: Discovering organophosphate bioscavenger characteristics among low molecular weight proteins. Sci Rep 2016, 6, 37175.

18. Thompson, C. M.; Prins, J. M.; George, K. M., Mass spectrometric analyses of organophosphate insecticide oxon protein adducts. Environ Health Perspect 2010, 118 (1), 11-9.

19. Casida, J. E.; Quistad, G. B., Serine hydrolase targets of organophosphorus toxicants. Chem Biol Interact 2005, 157-158, 277-83.

20. Carmany, D.; Walz, A. J.; Hsu, F. L.; Benton, B.; Burnett, D.; Gibbons, J.; Noort, D.; Glaros, T.; Sekowski, J. W., Activity Based Protein Profiling Leads to Identification of Novel Protein Targets for Nerve Agent VX. Chem Res Toxicol 2017, 30 (4), 1076-1084.

21. Mercey, G.; Verdelet, T.; Renou, J.; Kliachyna, M.; Baati, R.; Nachon, F.; Jean, L.; Renard, P. Y., Reactivators of acetylcholinesterase inhibited by organophosphorus nerve agents. Acc Chem Res 2012, 45 (5), 756-66.

22. Berry, W. K.; Davies, D. R., Factors influencing the rate of "aging" of a series of alkyl methylphosphonyl-acetylcholinesterases. The Biochemical journal 1966, 100 (2), 572-576.

23. Li, H.; Schopfer, L. M.; Nachon, F.; Froment, M. T.; Masson, P.; Lockridge, O., Aging pathways for organophosphate-inhibited human butyrylcholinesterase, including novel pathways for isomalathion, resolved by mass spectrometry. Toxicol Sci 2007, 100 (1), 136-45.

24. Ordentlich, A.; Barak, D.; Kronman, C.; Ariel, N.; Segall, Y.; Velan, B.; Shafferman, A., The Architecture of Human Acetylcholinesterase Active Center Probed by Interactions with Selected Organophosphate Inhibitors. Journal of Biological Chemistry 1996, 271 (20), 11953 11962.

25. Fukuto, T. R., Mechanism of action of organophosphorus and carbamate insecticides. Environ Health Perspect 1990, 87, 245-54.

26. Berman, J. D., Structural properties of acetylcholinesterase from eel electric tissue and bovine erythrocyte membranes. Biochemistry 2002, 12 (9), 1710-1715.

27. Guo, L.; Suarez, A. I.; Braden, M. R.; Gerdes, J. M.; Thompson, C. M., Inhibition of acetylcholinesterase by chromophore-linked fluorophosphonates. Bioorg Med Chem Lett 2010, 20 (3), 1194-7.

28. Janssen, A. P. A.; van der Vliet, D.; Bakker, A. T.; Jiang, M.; Grimm, S. H.; Campiani, G.; Butini, S.; van der Stelt, M., Development of a Multiplexed Activity-Based Protein Profiling Assay to Evaluate Activity of Endocannabinoid Hydrolase Inhibitors. ACS Chem Biol 2018, 13 (9), 2406-2413.

29. Gillet, L. C.; Namoto, K.; Ruchti, A.; Hoving, S.; Boesch, D.; Inverardi, B.; Mueller, D.; Coulot, M.; Schindler, P.; Schweigler, P.; Bernardi, A.; Gil-Parrado, S., In-cell selectivity profiling of serine protease inhibitors by activity-based proteomics. Mol Cell Proteomics 2008, 7 (7), 1241-53.

30. Sadler, N. C.; Bernstein, H. C.; Melnicki, M. R.; Charania, M. A.; Hill, E. A.; Anderson, L. N.; Monroe, M. E.; Smith, R. D.; Beliaev, A. S.; Wright, A. T., DinitrogenaseDriven Photobiological Hydrogen Production Combats Oxidative Stress in \&1t;span class=\&quot;named-content genus-species\&quot; id=\&quot;named-content1\&quot;\&gt;Cyanothece\&lt;/span\&gt; sp. Strain ATCC 51142. Applied and Environmental Microbiology 2016, 82 (24), 7227. 
31. Tyanova, S.; Temu, T.; Cox, J., The MaxQuant computational platform for mass spectrometry-based shotgun proteomics. Nat Protoc 2016, 11 (12), 2301-2319.

32. Caspi, R.; Billington, R.; Ferrer, L.; Foerster, H.; Fulcher, C. A.; Keseler, I. M.; Kothari, A.; Krummenacker, M.; Latendresse, M.; Mueller, L. A.; Ong, Q.; Paley, S.; Subhraveti, P.; Weaver, D. S.; Karp, P. D., The MetaCyc database of metabolic pathways and enzymes and the BioCyc collection of pathway/genome databases. Nucleic Acids Res 2016, 44 (D1), D471-80.

33. Wiedner, S. D.; Burnum, K. E.; Pederson, L. M.; Anderson, L. N.; Fortuin, S.; Chauvigne-Hines, L. M.; Shukla, A. K.; Ansong, C.; Panisko, E. A.; Smith, R. D.; Wright, A. T., Multiplexed activity-based protein profiling of the human pathogen Aspergillus fumigatus reveals large functional changes upon exposure to human serum. J Biol Chem 2012, 287 (40), 33447-59.

34. Wright, M. H.; Sieber, S. A., Chemical proteomics approaches for identifying the cellular targets of natural products. Nat Prod Rep 2016, 33 (5), 681-708.

35. Nomura, D. K.; Casida, J. E., Activity-based protein profiling of organophosphorus and thiocarbamate pesticides reveals multiple serine hydrolase targets in mouse brain. J Agric Food Chem 2011, 59 (7), 2808-15.

36. Fukuto, T. R., Relationships between the structure of organophosphorus compounds and their activity as acetylcholinesterase inhibitors. Bulletin of the World Health Organization 1971, 44 (1-3), 31-42.

37. Nolte, C.; Ammer, J.; Mayr, H., Nucleofugality and Nucleophilicity of Fluoride in Protic Solvents. The Journal of Organic Chemistry 2012, 77 (7), 3325-3335.

38. Long, J. Z.; Cravatt, B. F., The metabolic serine hydrolases and their functions in mammalian physiology and disease. Chem Rev 2011, 111 (10), 6022-63.

39. Richards, P. G.; Johnson, M. K.; Ray, D. E., Identification of acylpeptide hydrolase as a sensitive site for reaction with organophosphorus compounds and a potential target for cognitive enhancing drugs. Molecular Pharmacology 2000, 58 (3), 577-583.

40. Timur, Z. K.; Akyildiz Demir, S.; Seyrantepe, V., Lysosomal Cathepsin A Plays a Significant Role in the Processing of Endogenous Bioactive Peptides. Front Mol Biosci 2016, 3 , 68 .

41. Jeong, J. K.; Diano, S., Prolyl carboxypeptidase and its inhibitors in metabolism. Trends Endocrinol Metab 2013, 24 (2), 61-7.

42. Grau, S.; Baldi, A.; Bussani, R.; Tian, X.; Stefanescu, R.; Przybylski, M.; Richards, P.; Jones, S. A.; Shridhar, V.; Clausen, T.; Ehrmann, M., Implications of the serine protease HtrA1 in amyloid precursor protein processing. Proc Natl Acad Sci U S A 2005, 102 (17), 60216.

43. Oka, C.; Tsujimoto, R.; Kajikawa, M.; Koshiba-Takeuchi, K.; Ina, J.; Yano, M.; Tsuchiya, A.; Ueta, Y.; Soma, A.; Kanda, H.; Matsumoto, M.; Kawaichi, M., HtrA1 serine protease inhibits signaling mediated by Tgfbeta family proteins. Development 2004, 131 (5), 1041-53.

44. Wei, E.; Gao, W.; Lehner, R., Attenuation of adipocyte triacylglycerol hydrolase activity decreases basal fatty acid efflux. J Biol Chem 2007, 282 (11), 8027-35.

45. Moreau, H.; Moulin, A.; Gargouri, Y.; Noel, J. P.; Verger, R., Inactivation of gastric and pancreatic lipases by diethyl p-nitrophenyl phosphate. Biochemistry 1991, 30 (4), 10371041. 
46. Nomura, D. K.; Blankman, J. L.; Simon, G. M.; Fujioka, K.; Issa, R. S.; Ward, A. M.; Cravatt, B. F.; Casida, J. E., Activation of the endocannabinoid system by organophosphorus nerve agents. Nat Chem Biol 2008, 4 (6), 373-8.

47. Hoover, H. S.; Blankman, J. L.; Niessen, S.; Cravatt, B. F., Selectivity of inhibitors of endocannabinoid biosynthesis evaluated by activity-based protein profiling. Bioorg Med Chem Lett 2008, 18 (22), 5838-41.

48. Long, J. Z.; Li, W.; Booker, L.; Burston, J. J.; Kinsey, S. G.; Schlosburg, J. E.; Pavon, F. J.; Serrano, A. M.; Selley, D. E.; Parsons, L. H.; Lichtman, A. H.; Cravatt, B. F., Selective blockade of 2-arachidonoylglycerol hydrolysis produces cannabinoid behavioral effects. Nat Chem Biol 2009, 5 (1), 37-44.

49. Nomura, D. K.; Casida, J. E., Lipases and their inhibitors in health and disease. Chem Biol Interact 2016, 259 (Pt B), 211-222.

50. Hao, Z.; Zhang, Z.; Lu, D.; Ding, B.; Shu, L.; Zhang, Q.; Wang, C.,

Organophosphorus Flame Retardants Impair Intracellular Lipid Metabolic Function in Human Hepatocellular Cells. Chem Res Toxicol 2019.

51. Casida, J. E.; Nomura, D. K.; Vose, S. C.; Fujioka, K., Organophosphate-sensitive lipases modulate brain lysophospholipids, ether lipids and endocannabinoids. Chem Biol Interact 2008, 175 (1-3), 355-64.

52. Slotkin, T. A.; Seidler, F. J., Comparative developmental neurotoxicity of organophosphates in vivo: transcriptional responses of pathways for brain cell development, cell signaling, cytotoxicity and neurotransmitter systems. Brain Res Bull 2007, 72 (4-6), 232-74.

53. Costa, L. G.; Cole, T. B.; Vitalone, A.; Furlong, C. E., Measurement of paraoxonase (PON1) status as a potential biomarker of susceptibility to organophosphate toxicity. Clin Chim Acta 2005, 352 (1-2), 37-47.

54. Muthukrishnan, S.; Shete, V. S.; Sanan, T. T.; Vyas, S.; Oottikkal, S.; Porter, L. M.; Magliery, T. J.; Hadad, C. M., Mechanistic Insights into the Hydrolysis of Organophosphorus Compounds by Paraoxonase-1: Exploring the Limits of Substrate Tolerance in a Promiscuous Enzyme. J Phys Org Chem 2012, 25 (12), 1247-1260.

55. Stone, R., How to defeat a nerve agent. Science 2018.

56. Worek, F.; Thiermann, H.; Wille, T., Oximes in organophosphate poisoning: 60 years of hope and despair. Chem Biol Interact 2016, 259 (Pt B), 93-98.

57. Cabal, J.; Kuca, K.; Kassa, J., Specification of the structure of oximes able to reactivate tabun-inhibited acetylcholinesterase. Basic Clin Pharmacol Toxicol 2004, 95 (2), 81-6.

58. Wong, L.; Radić, Z.; Brüggemann, R. J. M.; Hosea, N.; Berman, H. A.; Taylor, P., Mechanism of Oxime Reactivation of Acetylcholinesterase Analyzed by Chirality and Mutagenesis $\dagger$. Biochemistry 2000, 39 (19), 5750-5757.

59. Chambers, J. E.; Meek, E. C.; Chambers, H. W., Novel brain-penetrating oximes for reactivation of cholinesterase inhibited by sarin and VX surrogates. Ann N Y Acad Sci 2016, $1374(1), 52-8$.

60. Cadieux, C. L.; Wang, H.; Zhang, Y.; Koenig, J. A.; Shih, T. M.; McDonough, J.; Koh, J.; Cerasoli, D., Probing the activity of a non-oxime reactivator for acetylcholinesterase inhibited by organophosphorus nerve agents. Chem Biol Interact 2016, 259 (Pt B), 133-141.

61. de Koning, M. C.; Horn, G.; Worek, F.; van Grol, M., Discovery of a potent non-oxime reactivator of nerve agent inhibited human acetylcholinesterase. Eur J Med Chem 2018, 157, 151-160. 
62. Masson, P.; Nachon, F., Cholinesterase reactivators and bioscavengers for pre- and postexposure treatments of organophosphorus poisoning. J Neurochem 2017, 142 Suppl 2, 26-40.

63. Albuquerque, E. X.; Pereira, E. F.; Aracava, Y.; Fawcett, W. P.; Oliveira, M.; Randall, W. R.; Hamilton, T. A.; Kan, R. K.; Romano, J. A., Jr.; Adler, M., Effective countermeasure against poisoning by organophosphorus insecticides and nerve agents. Proc Natl Acad Sci US A 2006, 103 (35), 13220-5.

64. Cho, C. M.; Mulchandani, A.; Chen, W., Altering the substrate specificity of organophosphorus hydrolase for enhanced hydrolysis of chlorpyrifos. Appl Environ Microbiol 2004, 70 (8), 4681-5.

65. Jackson, C. J.; Carville, A.; Ward, J.; Mansfield, K.; Ollis, D. L.; Khurana, T.; Bird, S. B., Use of OpdA, an organophosphorus (OP) hydrolase, prevents lethality in an African green monkey model of acute OP poisoning. Toxicology 2014, 317, 1-5.

66. Hiblot, J.; Gotthard, G.; Chabriere, E.; Elias, M., Characterisation of the organophosphate hydrolase catalytic activity of SsoPox. Sci Rep 2012, 2, 779.

67. Doctor, B. P.; Saxena, A., Bioscavengers for the protection of humans against organophosphate toxicity. Chem Biol Interact 2005, 157-158, 167-71.

68. Saxena, A.; Sun, W.; Luo, C.; Myers, T. M.; Koplovitz, I.; Lenz, D. E.; Doctor, B. P., Bioscavenger for protection from toxicity of organosphosphorus compounds. Journal of Molecular Neuroscience 2006, 30 (1), 145-147.

69. Vizcaino, J. A.; Csordas, A.; del-Toro, N.; Dianes, J. A.; Griss, J.; Lavidas, I.; Mayer, G.; Perez-Riverol, Y.; Reisinger, F.; Ternent, T.; Xu, Q. W.; Wang, R.; Hermjakob, H., 2016 update of the PRIDE database and its related tools. Nucleic acids research 2016, 44 (D1), D44756. 